\title{
XXXI. On the cheapest form of light, from studies at the Allegheny Observatory
}

\section{S. P. Langley \& F. W. Very}

To cite this article: S. P. Langley \& F. W. Very (1890) XXXI. On the cheapest form of light, from studies at the Allegheny Observatory, Philosophical Magazine Series 5, 30:184, 260-280, DOI: 10.1080/14786449008620021

To link to this article: http://dx.doi.org/10.1080/14786449008620021

曲 Published online: 08 May 2009.

Submit your article to this journal $[\pi$

Џ Article views: 2

Q View related articles $\square$ 
of an accurate number being obtained in this way. The figure obtained is about $51 \times 10^{6}$, a value which agrees with the observations better than that found by experiment.

I should add that I do not attach any importance to the diserepancies referred to. The experiments were made mainly with the view of showing the oscillating spark to an audience more clearly than is possible by the method of Dr. Lodge. For the purpose of measurement a window-glass condenser is not suitable at all, and I do not think the rotating lenses are so suitable as the method employed by Dr. Lodge, in which the plate itself is made to rotate in its own plane, for then the centre can be determined with the greatest accuracy.

The actual gain in number of sparks produced by the trap was found by making three experiments, in which all the conditions were the same except those specified.
A. No trap . . $\frac{1}{10}$ inch spark
B. No trap . $\cdot \frac{1}{2} 0$ inch spark
C. Trap giving $\left.\begin{array}{l}\text { potential } \\ \text { of A. }\end{array}\right\} \frac{1}{20}$ inch spark 37
32 elementary sparks. 29 "

I should in conclusion state that the measurements given at the end of these notes were made after the meeting of the Physical Society at which the paper was read, and that some other additions have been made to the fourth part of these notes.

XXXI. On the Cheapest Form of Light, from studies at the Allegheny Observatory. By S. P. Langlea and F. W. VERY *.

THE object of this memoir is to show, by the study of the 1 radiation of the fire-fly, that it is possible to produce light without heat other than that in the light itself; that this is actually effected now by nature's processes; and that these are cheaper than our industrial ones in a degree hitherto unrealized. By "cheapest" is here meant the most economical in energy, which for our purpose is nearly synonymous with heat; but as a given amount of heat is producible by a a known expenditure of fuel at a known cost, the word

* Communicated by the Authors, to whom we are liliewise indebted for the clichés. 
"cheapest" may also here be taken with little error in its ordinary economic application.

We recall that in all industrial methods of producing light there is involved an enormous waste, greatest in sources of low temperature, like the candle, lamp, or even gas-illumination, where, as I have already shown, it ordinarily exceeds 99 parts in the 100 ; and least in sources of high temperature, like the incandescent light and electric arc, where yet it is still immense, and amounts, even under the most favourable conditions, to very much the larger part.

It has elsewhere * been stated that for a given expense at least one hundred times the light should in theory be obtainable that we actually get by the present most widely used methods of illumination. This, it will be observed, is given as a minimum value, and it is the object of the present research to demonstrate that not only this possible increase, but one still greater, is actually obtained now in certain natural processes, which we know of nothing to prevent our successfully imitating.

It is now universally admitted that wherever there is light, there has been expenditure of heat in the production of radiation existing in and as the luminosity itself, since both are but forms of the same energy; but this visible radiant heat which is inevitably necessary, is not to be considered as waste. The waste comes from the present necessity of expending a great deal of heat in invisible forms before reaching even the slightest visible result, while each increase of the light represents not only the small amount of heat directly concerned in the making of the light itself, but a new indirect expenditure in the production of invisible calorific rays. Our eyes recognize heat mainly as it is conveyed in certain rapid æthereal vibrations associated with high temperatures, while we have no usual way of reaching these high temperatures without passing through the intermediate low ones; so that if the vocal production of a short atmospheric vibration were subject to analogous conditions, a high note could never be produced until we had passed through the whole gamut, from discontinuous sounds below the lowest bass, up successively through every lower note of the scale till the desired alto was attained.

- There are certain phenomena, long investigated, yet little

* See results of an investigation by S. P. Langley, read before the National Academy in 1883, and given in 'Seience" for Jume 1, 1883, where it is shown that in the ordinary Argand-burner gas-flame indetinitely over 99 per cent. of the radiant energy is (for illumination purposes) waste. 
understood, and grouped under the general name of "phosphorescent" which form an apparent exception to this rule, especially where nature employs them in the living organism, for it seems very difficult to believe that the light of a fire-fly, for instance, is accompanied by a temperature of $2000^{\circ}$ Fahr., or more, which is what we should have to produce to gain it by our usual processes. That it is, however, not necessarily impossible, we may infer from the fact that we can by a known physical process produce a still more brilliant light without sensible heat where we are yet sure that the temperature exceeds this. No sensible heat accompanies the fire-fly's light any more than need accompany that of the Geissler tube; but this might be the case in either instance, even though heat were there, owing to its minute quantity, which seems to defy direct investigation. It is usually assumed, with apparent reason, that the insect's light is produced without the invisible heat that accompanies our ordinary processes ; and this view is strengthened by study of the fire-fly's spectrum, which has been frequently observed to diminish more rapidly toward the red than that of ordinary flames.

Nevertheless, this, though a highly probable and reasonable assumption, remains assumption rather than proof, until we can measure with a sufficiently delicate apparatus the heat which accompanies the light, and learn not only its quantity, but, what is more important, its quality. Apart from the scientific interest of such a demonstration is its economic value, which may be inferred from what has already been said. I have therefore thought it desirable to make the light of the fire-fly the subject of a new research, in which it is endeavoured to make the bolometer supplement the very incomplete evidence obtainable from the visible spectrum.

As we may learn from elementary treatises, phenomena of phosphorescence are common to insects, fishes, mollusks, vegetables, and organic and mineral matter. Among luminous insects, the fire-fly of our fields is a familiar example, though others of the species attain greater size, and perhaps greater intrinsic brilliancy, especially the Pyrophorus noctilucus, Linn., found in Cuba and elsewhere. Its length is about 37 millim., width 11 millim., and it has, like other Pyrophori, three lightreservoirs - two in the thorax and one in the abdomen. To procure this Cuban fire-fly, I invoked the aid of the Smithsonian Institution, and through the kindness of Professor Felipe Poey, of Havana, and Señor Albert Bonzon, of Santiago de Cuba, in the Island of Cuba, living specimens of the $P$. noctilucus were received here during the summer of 1889 . I have also to acknowledge my obligations to Professor C. V. 
Riley, and to Professor L. A. Howard, to whose knowledge and kind care I am doubly indebted.

After a preliminary spectral examination in Washington, I found it more convenient to continue the research at the Allegheny Observatory by means of the very special apparatus supplied by the liberality of the late William Thaw, of Pittsburgh, for researches in the lunar heat-spectrum*. Photometric measurements throughout the spectrum of the insect's light were also made.

I have indicated the steps of the investigation; but the experiments bave been so largely and so intelligently made by Mr. F. W. Very, that it is just to consider him as an associate rather than an assistant in the researches. I shall accordingly in what follows not discriminate between what each has contributed.

\section{Historical Notes.}

We make no attempt to give any bibliography of the subject, and these notes are confined to what seems important in the history of the physical side of it.

Nathaniel Hulme †.-Exp. 6. A dead shining glow-worm was put upon water contained in a wide-mouthed phial, at the temperature of $58^{\circ}$. The phial was then sunk in boiling-hot water; and as the heat communicated itself to the contents of the phial, the light of the glow-worm became much more vivid.

Exp. 7. Another lucid dead glow-worm was put into warm water at $114^{\circ}$, to see if that degree of heat would extinguish the light; but, on the contrary, its glowing property was augmented. All the water was then poured off, yet the insect continued to shine for some length of time.

Exp. 8. Two living glow-worms were put into a one-ounce phial, with a glass stopple ; and though they were perfectly dark at the time, yet if the phial were briskly rubbed with a silken or linen handkerchief till it became pretty warm, it seldom failed to make them display their light very finely. This experiment was very frequently repeated. It had the same illuminating effect upon the light of a dead glowworm.

Exp. 9. The complete influence of 212 degrees of heat was now applied to the light of a glow-worm by pouring upon one when dead, but in a luminous state, some boiling water.

\section{p. 112}

* Deseribed in the Memoirs of the National Academy, vol. iv. part 2,

† Phil. Trans. Roy. Soc. Lond. vol. xc. pp. 180-181 (1800). 
Its light was instantly extinguished thereby, and did not revive. The experiment was repeated, and with the same result.

Macaire * (quoted by Becquerel) found that the luminous matter taken from the body of a glow-worm and heated, increased in brilliancy up to a temperature of about $41^{\circ} \mathrm{C}$., after which the light diminished, became reddish, and ceased at $52^{\circ} \mathrm{C}$. An electric current increased the luminosity in both the living insect and in the luminous part separated from the remainder of the body, but ceased to have any effect in a vacuum. Oxygen and carbon monoxide increased the light of the living insect and of the luminous matter taken from its body; but the light ceased in a vacuum, in hydrogen, in carbon dioxide, in sulphurous anhydride, and in sulphuretted hydrogen.

Carus $\dagger$ observed that the luminous matter taken from the body of the glow-worm ceases to shine when dried, but glows again when moistened.

Matteucci $\ddagger$ found that the phosphorescent substance of the Italian glow-worm (Lampyris italica) soon ceased to glow in hydrogen or in carbon dioxide, but shone decidedly brighter in oxygen than in air, the oxygen being consumed and carbon dioxide appearing. He drew the conclusion that the prodnetion of light in this insect is entirely due to the combination of oxygen with carbon, which is one of the elements of the phosphorescent matter. The greatest brilliancy occurred at a temperature of $37^{\circ}$ or $38^{\circ}$ Cent., but all phosphorescence ceased above $50^{\circ}$ or below $-b^{\circ}$ Cent.

Robert $\$$ found that a glow-worm cut in halves continued to glow for half an hour, when the light ceased, but commenced again on the near approach of a candle, and continued as bright as ever for thirty-six hours, after which it was impossible to renew it.

Pasteur $\|$ has examined the spectra of our Pyrophorus without finding any appearance of bright or dark lines. He states that M. Gernez has made a similar observation on the spectrum of the glow-worm.

Becquerel 9 gives a good summary of the results of previous observers. Since phosphorescent solids give banded spectra,

* Bibliothèque Universelle de Genève, 1821.

$\dagger$ Analecten zur Natur- und Heilkunde, Leipzig, 1829 ; see also Comptes Rendus, lix. p. 607 (1864).

† Ann. de Chim. et de Phys: [3] ix. p. 71 (1843); also in Comptes Rendus, xvii. p. 309.

\$ Comptes Rendus, xvii. p. 627 (1843). N Ibid. lix. p. 509 (1843).

I La Lumière, 1867. 
and thus differ from ignited solids and liquids, which have continuous spectra, M. Becquerel concludes, from the apparent continuity of the spectrum of the light from phosphorescent animals, that their light approaches nearer to that of ordinary incandescence-a deduction which the following result renders unnecessary.

C. A. Young" states that the "common" fire-fly gives a continuous spectrum, extending from a little above Fraunbofer's line $\mathrm{C}$ in the scarlet to about $\mathrm{F}$ in the blue, gradually fading out at the extremities. He observes that it is noticeable that precisely this portion of the spectrum is composed of rays which, while they more powerfully than any others affect the organs of vision, produce hardly any thermal or actinic effect. In other words, very little of the energy expended in the flash of the fire-fly is wasted.

(This is a most important and interesting inference; but it will be observed that this is necessarily rather assumed as highly probable than actually demonstrated, since the method did not permit the dealing with the invisible rays except by inference.)

It is quite different with our artificial methods of illumination. In the case of an ordinary gas-light, experiments show that at most one per cent. of the radiant energy consists of visible rays, the rest being invisible heat; that is to say, over ninety-nine per cent. of the gas is wasted in producing rays that do not help in making objects visible $†$.

Secchit at first thought that the spectrum of the glowworm was monochromatic, but, with an improved spectroscope, recognized that other colours were present, though feebly, and decided that the spectrum was sensibly continuous.

Quatrefages $\$$, in connexion with the paper of Secchi, remarks that the previous observations of Spallanzani and Macaire, repeated with much care by Mattencci and Becquerel, show beyond doubt that the light of glow-worms and elaters is due to slow combustion. Thus the light is extinguished in a vacuum and in irrespirable gases, it reappears in contact with the air, it is perceptibly increased by the presence of pure oxygen, it persists after the death of the creature, and finally it is accompanied by the generation of carbon dioxide. Nevertheless he points out that there is a distinct lind of phosphorescence in the marine Noctilucida, due to the con-

* The American Naturalist, Salem, 1870, vol, iii. p. 615 .

+ S. P. Langley has shown that the waste is in fact even greater than this; see 'Science,' vol. i. No. 17, p. 482 (1883).

$\dagger$ Comptes Rendus, Ixxv. p. 321 (1872). $\quad$ Ibid. p. 322 (1872). 
traction of muscular fibre, the shining tissue being seen through the translucent body-wall. This species of phosphorescence is increased by irritants, but is independent of the presence of oxygen, and is not extinguished or in any way modified by hydrogen or by carbon dioxide.

Robin and Laboulbene ${ }^{*}$ find the luminous organs of $P$. noctilucus composed of irregularly polyhedral cells, 0.04 to 0.06 millim. thick, between which pass very numerous fine tracheæ and nerves. The inner face of the organ is composed of adipose tissue, and the outer of a transparent modification of the ordinary chitinous covering of the insect. The authors conclude that the light is due to chemical decomposition of a nitrogenous body with formation of crystalline urates.

Jousset de Bellesme $\uparrow$ finds that although the phosphorescent cells, when separated from the body of the insect, continue to glow for several hours, yet if crushed they instantly lose their illuminating power, which indicates that for the production of the light the living cells must retain their integrity, and that they are not mere reservoirs of a phosphorescent substance, but continuous generators of it. He surmises that the lightgiving substance may be phosphuretted hydrogen.

Meldola $\ddagger$ is quoted by Spiller $§$ as having examined the glow-worm spectrum and determined its approximate limits.

Conroy If finds the glow-worm's light green, and in a small direct-vision spectroscope, showing a continuous spectrum from $\mathrm{C}$ to $b$, appearing like a broad band of green light extending from $0^{\mu} .518$ to $0^{\mu} \cdot 587$, with a faint continuous spectrum into the red to $0^{\mu} 656$.

R. DuBois T.-Perhaps the most important of previous memoirs on phosphorescent insects is by this writer. It contains an account of photometric measures in wave-length scale, and also of heat-measures with the thermopile. The latter represent the only attempt even, in this direction, I know of, and seem to be judiciously made, but to be insufficient (on account of the limitations of such apparatus) to establish the author's conclusion that the light is accompanied by no sensible heat. This conclusion, we repeat, though very probably correct, does not seem to rest on the evidence of an apparatus of at all the necessary sensitiveness. This memoir, however, appears to be in general an excellent one, and well worthy the student's attention.

* Comptes Rendus, lxxvii. p. 511 (1873).

$\ddagger$ Proc. Entomol. Soc. p. iii. (1880).

+ Ibid.xc. p. $318(1880)$.

II Nature, vol. xxvi. p. 319 (1882).

\$ Nature, vol. xxvi. p. 343.

Il Bulletin de la Société Zoologique de France, parts 1, 2, and 3, 1886. 
From all these statements it is abundantly clear that not only physicists and chemists, but naturalists, have been led to conclude that this light is not associated indissolubly with any so-called vital principle or vital process, but that it is a result of certain chemical combinations, and that nothing forbids us to suppose it may be one day produced by some process of the laboratory or manufactory. With this conclusion in mind, we now proceed to observations meant to demonstrate the fact that this process (presumably discoverable but still unknown) gives light without invisible heat.

These observations are :-1. Photometric. 2. Thermal.

\section{Part I.-Photometric Observations.}

The first impression on viewing the light of the Pyrophorus noctilucus through a spectroscope is that it consists essentially of a broad band in the green and yellow, while with precaution we see this extending into and beyond the borders of the blue and orange, but not very greatly farther, and these have been taken by previous observers as its absolute limits. No one appears to have experimentally and distinctly answered the question, "Would the light not extend farther were it bright enough to be seen ?"; nor has it been proven as clearly as might be desired that the result depends on the quality rather than the quantity of the light, or given conclusive evidence, that if the light of the insect were as bright as that of the sun it would not extend equally far on either side of the spectrum.

It is impossible to increase the intrinsic brilliancy by any optical device, but if it be impossible to make the light of the insect as bright as that of the sun, it is on the other hand quite possible to make the light of the sun no brighter than that of the insect; and this would appear to be the first step in obtaining a definite proof that the apparently narrow limits of the insect's spectrum are due to the intrinsic quality of the light and not to its feeble intensity. The only conclusive method of determining this would appear to be to balance the light from the insect with that of a definite portion of sunlight by any ordinary photometric device; and having taken this sunlight as nearly equal as possible to that of the insect, though certainly not greater, to let this determined quantity fall on the slit of a spectroscope at the same time with the light from the insect, two spectra being formed one over the other in the same field and at the same time.

The actual doing this is not so easy as it might appear, owing to experimental difficulties connected with the insect, 
a part of which arises from the fact that its light is not only fitful but unequal, being of very varying intensities when not wholly intermittent.

The simplest way in which the experiment can be performed is perhaps the following :-

The insect is placed immediately in front of the slit of a spectroscope so that the light of its thoracic or abdominal portion falls upon the slit. This forms a narrow spectrum which should be brought into the lower or upper half of the field, the insect being attached to the spectroscopic apparatus in a position as nearly fixed as possible. The spectroscope is now placed with the axis of its collimator in the line of a ray of sunlight cast from a heliostat without. In the path of this ray is a screen with a circular diaphragm covered with ground glass ; a lens in front of the slit casts on one portion of it an image of the white circle formed by the ground glass, which image is the same size as the illuminating organ of the insect, and forms a spectrum of the same height in the reserved portion of the field. A suitable disposition of lenses placed between the glass screen and the siderostat enables any degree of illumination to be given to the former, from full sunlight to nearly absolute darkness. If the normal spectrum be studied, a grating is selected of such open ruling that the entire visible spectrum of the first order can be seen in the field, but the grating is first so placed that what is seen is not the spectra but the reflected image of the slit, the grating thus acting (at first) the part of a mirror; so that the observer first sees the two circles of light of approximately equal size and brilliancy, one formed by the insect, the other by the sunlight, and the light of this latter, by the arrangement of lenses between the screen and the siderostat, is then adjusted so that while remaining of the size of the insect, it is judged to have the same intrinsic brilliancy, or at any rate not a superior one.

The essential thing is that a photometric comparison shall be made of the two lights before the spectra are formed, and that under these conditions the sunlight is equal but not superior to that of the insect.

The necessary condition of equality of the two lights from which the spectra are to be formed having thus been secured, the grating is moved until the two spectra are brought into the field. The result of this direct test is that the solar spectrum when intrinsically of the same brightness, or even when clearly of less brightness than that of the insect, extends somewhat further toward the red and distinctly further toward the violet, the insect light being more intense than that of the 
sun for equal lights in the green, but ending more abruptly on the violet side.

It may be added that when the insect's light grew brighter, the increment appeared to be more in the blue end, or as if the average wave-length diminished with the intensity, but there was not opportunity to put this beyond doubt.

Photometrie observations in the prismatic spectrum were made previously to the adoption of the arrangement above detailed, the first being on July 1, 1889, using thoracic light. The insect was mounted on an adjustable stand to which it was attached loosely, so as to give it such freedom of motion as is needed to ensure its emitting the light. It was consequently necessary to re-adjust its position incessantly, and this necessity constitutes a very obvious difficulty. The thoracic light-spots are two ovals, each about 2 millim. by 1.5 millim. (see fig. 1). Their light is not so bright as the abdominal light, but much steadier, and, like that, of a decidedly greenish hue. One of these oval spots was placed over the centre of a slit, open just enough to receive the light, or about 1.5 millim. This slit was in the focus of a glass lens of 8 centim. aperture and 82 centim. focus, which acted as a collimator. The prism was a very large one of flint (faces 11.5 centim. high, 10.5 centim. wide), whose mounting included an automatic minimum-deviation attachment. 'The observing lens was similar to the collimator, with a lowpower eye-piece in whose field was a pair of heavy vertical

Fig. 1.

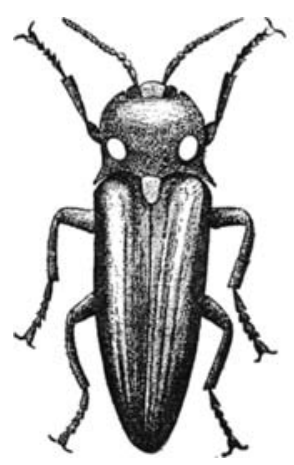

Fig. 2.

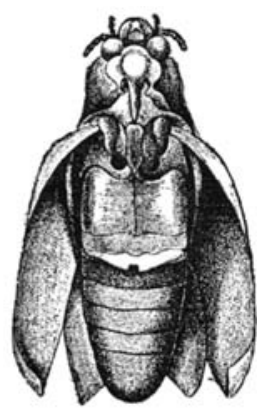

Pyrophorus noctilucus.

parallel wires. The whole was mounted on the spectrometer, primarily designed for bolometric measures and fully described Phil. Mag. S. 5. Vol. 30. No. 184. Sept. 1890. 
elsewhere*. The insect turned so as to show the abdominal light is depicted in fig. 2.

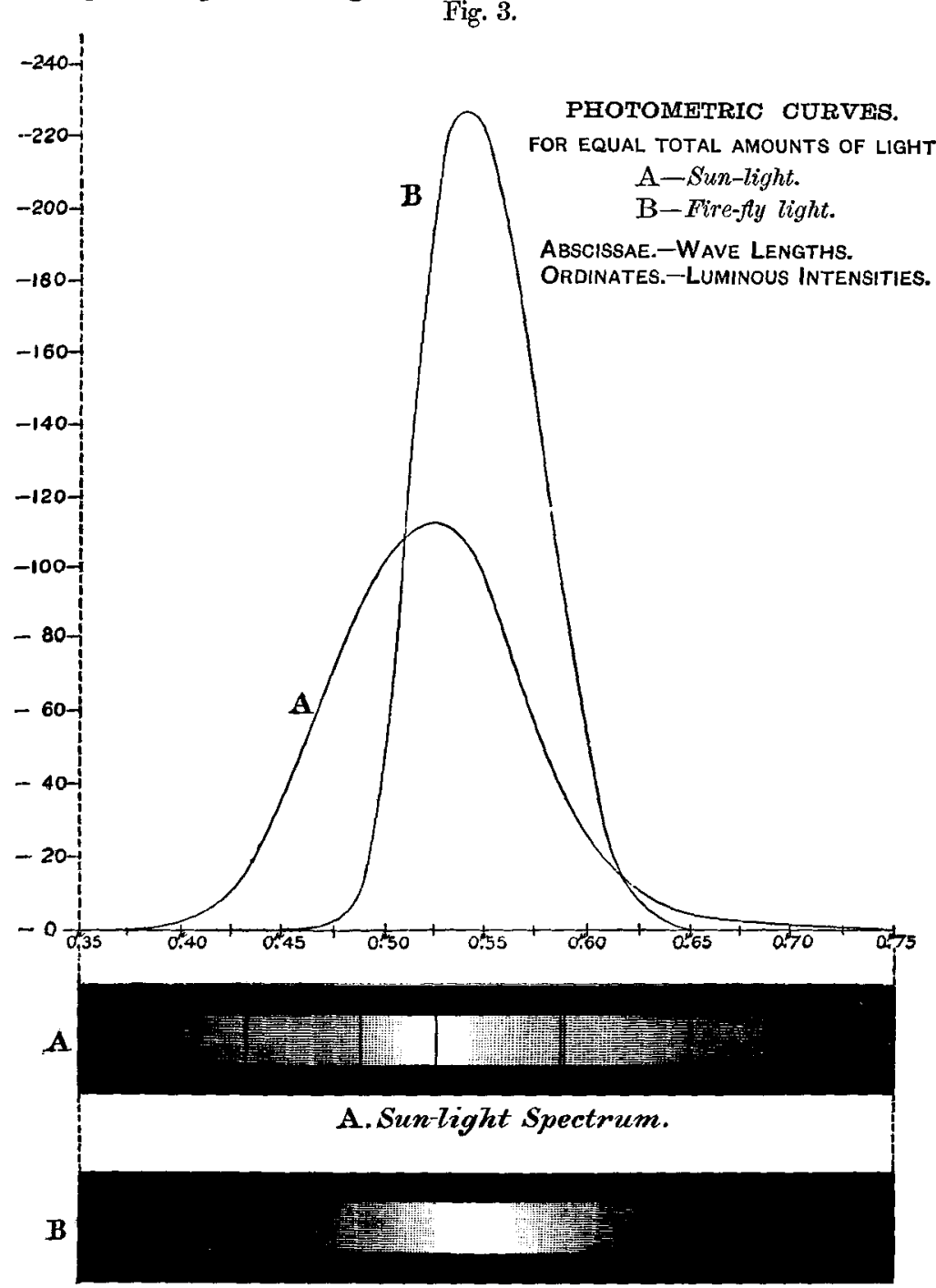

\section{B. Fire-fly Spectrum.}

The observer waited for some time in a wholly darkened room, and to the eye, thus rendered sensitive, the visible spectrum, before magnification, was about 2 millim. high and

* See this Journal, March 1883, p. 173. 
20 millim. long, the parallel wires being distinctly visible in the indigo at a setting of $45^{\circ} 25^{i}$, corresponding to a wavelength of $0^{\mu} \cdot 468$, and in the red at $43^{\circ} 53^{\prime}$, corresponding to $0^{\mu} \cdot 640$. The spectrum then was visible from a little beyond $F$ to near $C$, or through a range of $0^{\mu \cdot 172}$. As might have been anticipated from the greenish colour of the light, the maximum brilliancy was in the green near $\mathrm{E}$, or near wavelength $0^{\mu} \cdot 53^{*}$. From this point the light fell away on both sides more rapidly than in the solar spectrum. (See fig. 3, A, B.)

July 2.-A comparison of the spectra of the thoracic and of the abdominal light gave the latter upon the average about double the intrinsic brightness of the former. This was only a crude estimate, but more exact methods under the limited time for experiment would have been useless, owing to the very fluctuating character of the light. In continuation of the photometric measurements of the preceding day on the thoracic light, this was compared with that from the flame of an ordinary Bunsen burner at its greatest luminosity, whose area was limited by a diaphragm to that of the size of the thoracic light. 'The light from the base of this luminous flame (height of flame about 3.5 centim., air shut off at base of hurner) gave a continuous spectrum, which in these first comparisons was alternated with that of the insect. The spectra were judged to be equal in the blue and the red, but that of the insect was much brighter in the green. Again, a spectrum being formed from light taken midway between the base and point of the flame was fonnd to be everywhere too bright, but especially so in the red.

July 3.-Continuation of photometric measures but with abdominal light.

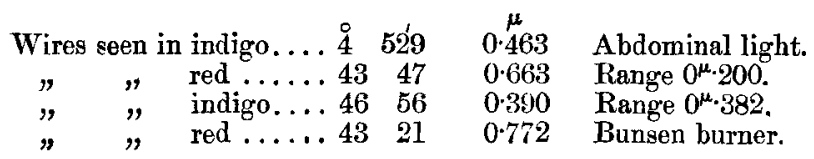

(Luminous flame 4 centim. high, at point one third down from top, just within inner and slightly darker cone, seen through hole 2.5 millim. in diameter). Under these circumstances the spectrum of the insect's light was in the green a fair match for that of the burner, elsewhere the latter was brighter but not very greatly so. Since the insect's spectrum was followed through $0^{\mu} \cdot 18$ with the thoracic light, while with that of the same character but double the brightness it was followed only through a very little more, or $0^{\mu} \cdot 20$, and

* In the normal heat-spectrum the maximum has a wave-length $0^{\mu} \cdot 57$. 
while at the same time that of a but slightly brighter artificial flame was followed through nearly double or $0^{\mu} \cdot 38$, it seems probable that the insect's light actually ceases near the given limits, and does not merely disappear from the inability of the eye to follow a diminishing light. While we observe from these first photometric measures that the insect's spectrum has undoubtedly a decided maximum in the green, we are led to infer that this spectrum is very probably of the nature of a broad band stretching from beyond $\mathrm{F}$ to near $\mathrm{C}$ where it terminates, and this very important inference we shall see confirmed later by other and more exact measures.

August 5.-Comparison of relative brightness in different parts of spectrum of abdominal light with that from a student's lamp.

A spectrometer supplied with means * for bringing into the same field the spectra of two different lights, formed by a Rutherfurd grating of 17296 lines to the inch (instead of the prism) was employed for this purpose. The upper half of the slit received the insect's light, the lower half a beam from the brightest part of the Argand flame, which had passed through two Nicol's prisms, one of which was attached to a divided circle. The two spectra were then seen in the same field with their edges in exact juxtaposition. In the field of the observing telescope was a slit 1 millim. wide, subtending not quite $9 \cdot 5$ (minutes of arc), which allowed light having a range of wave-length of about $0^{\mu} \cdot 01$ to pass. The spectrum of the lamp-light was brigbter in every part of the field though in unequal degrees till it was diminished by turning the Nicol's prism. The angle through which the prism was turned to produce equality having been noted, the values deduced from the ordinary formula (transmitted light $=l \cos ^{2} \alpha$, the angle $\alpha$ being $90^{\circ}$ when the light is diminished as much as possible by crossing the planes of the Nicols at right angles) are as follows, where the fractions are those by which the brightness of the lamp spectrum at the various points is to be multiplied to produce equality with the insect spectrum.

\begin{tabular}{|c|c|c|c|c|c|c|c|c|}
\hline $\begin{array}{l}\text { Part of spectrum } \\
\text { corresponding to } \\
\text { centre of slit at } \\
\text { focus of observing } \\
\text { teleseope. }\end{array}$ & $\begin{array}{c}\text { Blue- } \\
\text { green } \\
\text { yery } \\
\text { near } \\
\text { F. }\end{array}$ & $\begin{array}{c}\text { Green } \\
\text { near } \\
\text { b. }\end{array}$ & $\begin{array}{l}\text { Green } \\
\text { near } \\
\text { E. }\end{array}$ & $\begin{array}{l}\text { Yellow } \\
\text { green. }\end{array}$ & Citron. & Yellow. & $\begin{array}{c}\text { Orange- } \\
\text { yellow } \\
\text { near } \\
\text { D. }\end{array}$ & Orange. \\
\hline Wave-length...... & $\stackrel{\mu}{\alpha \cdot 49}$ & $\begin{array}{c}\mu \\
0.51\end{array}$ & $\stackrel{\mu}{0_{0}^{\prime} 53}$ & $\stackrel{\mu}{0.54}$ & $\stackrel{\mu}{0.56}$ & $\stackrel{\mu}{0.58}$ & $\stackrel{\mu}{0.59}$ & $\stackrel{\mu}{0} 60$ \\
\hline Brightness $\ldots$ & 0.02 & $0 \cdot 21$ & $0 \cdot 34$ & $0 \cdot 37$ & $0 \cdot 24$ & $0 \cdot 19$ & $0 \cdot 17$ & 0.09 \\
\hline
\end{tabular}

* Alluded to but not fully described in the Am. Journ. Sci., A ugust 1877. 
Owing to the motion of the insect and the varying brilliancy of the light emitted, these figures (each of which is the result of the mean of several trials including at least two measures) still leave much to be desired. The supply of the insects, which had been procured and maintained alive with difficulty, however, did not allow of the experiments being further prolonged, nor of the securing a direct comparison with the solar spectrum. The value of each part of the lamp spectrum having, however, been independently determined with all possible exactness in terms of the solar spectrum, we are enabled to exhibit a comparison of the latter with the insect spectrum so as to show them together (fig. 3, A and B). It is assumed that the same amount of luminous intensity (i.e. energy in terms of vision as determined by purely photometric methods) is taken whether from the sun or the insect. The subjoined curves (fig. 3, A) show the solar and the insect luminosity throughout the visible spectrum on the preceding assumption of the intrinsic equality, a result which, however, might be liable to a slight correction of the relative places of the maxima if a direct comparison with sunlight were obtained. The important fact, however, seems to be brought out almost bevond question, that when spectra are formed from two equal lights, one from the sun the other from the insect, the latter's spectrum terminates both at an upper and a lower limit at which the solar light is still conspicuous. The conclusion follows that the insect spectrum is lacking in the rays of red luminosity and presumably in the infra-red rays, usually of relatively great heat; or that it seems probable that we have here light without heat, other than that heat which the luminosity itself comprises and which is but another name for the same enegy.

Any other supposition would apparently involve the hypothesis that the spectrum, which we have seen end at the red, has a renewal in the invisible infra-red where the main portion of the solar heat and that of all ordinary illuminants is known to exist. Although this last hypothesis cannot be considered to have much weight, and though we are led to agree with previous observers that it may be assumed with much probability that the ordinary invisible heat would, if we had means to observe it, be found unassociated with the fire-fly's light, yet this assumption is itself far from being proof, and in view of the great importance of the conclusions in question, we shall now try whether it be possible to settle the point by thermal measures with the bolometer. 


\section{Part II.--Thermal Observations.}

To give an idea of the amount of heat at our disposition for experiment, and of the actual minuteness of the radiation which proceeds from even the most luminous tropical insect, we may say that if that rate of radiation from a lampblack surface 1 square centim. in area, which represents the amount of heat necessary to raise 1 grm. of water $1^{\circ} \mathrm{C}$. in 1 minute (i.e. one small calorie), be taken as unity, then the luminous radiation of the fire-fly's heat per square centim. of exposed luminous surface, as we have found, is about 0.0004 calorie in 10 seconds, and the total luminous radiation from the most powerfully illuminating light-spot of the insect (the abdominal one) will not exceed 0.00007 calorie in the same time. But a small portion of this could fall upon the bolometer, and that which actually reached it during the time (10 seconds) required for each observation was sufficient only to affect an ordinary mercurial thermometer having a bulb 1 centim. in diameter by rather less than $0^{\circ} .0000023$, or by less than $\frac{1}{400000}$ of one degree Centigrade.

We have just mentioned that the total amount of heatradiation upon which we have to make our investigation represents less than 100000 calorie, while that portion of this which falls upon the apparatus would, in the time of one operation, only raise the temperature of an ordinary mercurial thermometer by less than $\frac{1}{40000} \overline{0}$ degree; and we have first to notice the difficulty that in case invisible heat exists in company with the light (and it certainly does exist in ordinary emanations from the surface of any living creature independent of phosphorescence), we have in this minute radiation heat of two different kinds, both invisible, and which it is yet indispensable for us to discriminate.

We are helped to do this by the consideration that while the insect, like any non-luminous one, must emit " animal heat "from all its surface, its general surface-temperature is certainly low, since it feels cold to the hand, whose greater warmth excites it to shine. This heat, then, corresponds to a temperatnre much below $50^{\circ} \mathrm{C}$.; and such temperatures must, as we have shown in other memoirs, be accompanied by the emission of waves whose length relegates them to quite another spectral region to that in which the invisible heat associated with light mainly appears. We can then discriminate the rays of this invisible "animal " heat without the formation of a heat-spectrum, by their inability to pass through a glass which transmits with comparative freedom radiant heat whose wave-length is less than $3^{\mu}$, the latter including the region 
where, if there be invisible heat radiated with the light, it must mainly lie.

The heat in the spectral region of the infra-red we are considering we know in advance must be, if it bear any sort of relation to the light, almost immeasurably small; and, in fact, it defied at first all attempts to obtain not merely a quantitative measurement, but even any certain experimental evidence of its existence. At last, upon July 24, with the arrival of a new stock of over two dozen insects, and with the aid of experience derived from previous failures, these heat-measures were resumed. For the first described, the thoracic light is taken.

The insect was placed 125 centim. from the mirror of 25.4 centim. aperture and 73.4 centim. focus, so that its image was formed at 178 centim. and enlarged about $1 \cdot 42$ diameter, when a small portion of it filled an aperture equal to the bolometer employed, which was selected from the most sensitive of those used in previous researches in lunar heat, and had an aperture of 19 square millim. By the preceding arrangement of the mirror an image of one of the thoracic bright spots, with enough of the surrounding body to represent an area of about 13 square millim., was enlarged to nearly the surface of the bolometer.

Employing all the precautions taught by a multiplied experience, we obtained by a series of exposures of the bolometer to the insect-radiation a series of small but real galvanometerdeflexions which represent the excess of total heat-radiations from the insect over those from a metal plate of a temperature of about $25^{\circ} \mathrm{C}$. forming the background. These heat-radiations come jointly from the luminous spot (area 3 to 4 square millim.), and about 9 square millim. of the surrounding body. To determine their characters, we interposed a sheet of glass* which cut off all the observed heat. The heat from the luminous spectrum and from a spectral region below it extending to about $3^{\mu}(30,000$ tenth-meters) was known to be capable of passing through this glass. The evidence, then, is that there is no heat in the spectrum below this feeble radiation from the luminous thoracic region sufficient to be capable of affecting the apparatus, though this was so sensitive as to promptly respond to the feeble body-radiation from the somewhat larger section of the luminous and non-luminous surface.

\section{Continuation on Abdominal Heat.}

The insect's light, then, is unaccompanied (in the specimen

* Described in the memoir "On the Temperature of the Surface of the Moon," Mem. Nat. Acad. of Sciences, vol. iii., as "B." 
subject to this experiment) by any measurable heat; but to make it still more evident that this is due to the absence of heat below the red (body-heat not being in question), we now proceed to take an artificial fiame, occupying the same area as the radiating luminous part of the insect, and to see whether heat is observed in it. If the flame be no brighter than the insect, and the heat be nevertheless observed in it when in the insect heat is lacking, it is obvious that in the latter case none is observed, because (sensibly) none is emitted ; and this conclusion is reached, a fortiori, when the flame-light is less than that of the insect.

July 27 .-Through a circular a perture' 2.5 millim.in diameter there were passed alternately the total radiant heat and that transmitted by glass from a nearly non-luminous Bunsen-flame whose luminosity was very much fainter than that from the insects. On this day there seemed to be an exceedingly minute deflexion averging $\frac{1}{4}$ of one division of the galvanometer-scale from the total radiation of an equal portion of the abdominal light-spot of the insect, while from the flame there was a mean deflexion of $177 \cdot 5$ divisions, showing that the total heat-radiation from an equal area of a less luminous flame was many hundred times that from the luminous area of the insect.

Glass being interposed, the heat due to this Hame-radiation fell to 14.5 divisions, or about 8 per cent. of the original radiation, showing that of the quality of Bunsen-flame heat immediately in question (that above $3^{\mu}$ transmissible by glass) there was still something like 60 times that of the combined body and luminous radiation of the insect in the far less luminous flame. Subsequently, by the use of a lens giving greater concentration, measurable indications of insect-radiation above $3^{\mu}$, and therefore distinct from any possible body-heat, were obtained through glass, showing the flame-radiation of this quality from an equal area of the same intrinsic brillianey, $i$. e. invisible heat and of long wave-length, but shorter than $3^{\mu}$, to be about 400 times that of the insect.

These experiments were repeated with different luminous flames and with different insects on succeeding days. In some of them especially Iuminous insect specimens were secured, which, with favourable conditions of the galvanometer, gave very measurable deflexions on the latter. By a similar use of the glass to that described, it appeared that flames whose intrinsic brilliancy is nearly comparable to that of a point below the middle of the candle-flame, and whose total brilliancy is as exactly as possible comparable to that of the insect, give several hundred times the heat of the latter, even if we consider only that quality of heat which is found above $3^{\mu}$, 
while if we compare the total radiations (i.e. those directly observed without the use of the glass) the contrast is still stronger.

It follows that the insect-light is accompanied by approximately one four-hundredth part of the heat which is ordinarily associated with the radiation of flames of the luminous quality of those which were the subject of experiment. This value is confirmed by other methods which we do not give here. It will conduce to a clearer comprehension of this if we exhibit in a series of curves derived from our observations the spectral distribution of one unit of energy in the gas-flame spectrum (diagram 4, fig. 1); of the electric-arc spectrum (fig. 2); of the sun (fig. 3); and of the insect (fig. 4). In all these the abscissæ are the same, the portion between $0^{\mu \cdot 4}$ and $0^{\mu \cdot 7}$ (violet to red) showing the part of the energy utilized in light, while that from $0^{\mu \cdot} \cdot 7$ to $3^{\mu}$ shows the part wasted as invisible heat. The energy in each case being the same, the areas are the same, except that owing to the relative importance of the light heat-curve (fig. 4), only about $\frac{1}{20}$ of the latter can be shown in the limits of the plate.

The curves in fig. 3 deal with luminous intensity only, and give no means of drawing those economic conclusions which appear to follow from our experiments, and which the curves in diagram 4 supply. These curves all exhibit the spectrum on the normal scale, from that easily visible, lying between $0^{\mu} \cdot 4$ in the violet and $0^{\mu \cdot} \cdot 7$ in the red, then to $3^{\mu}$ near the limit of the glass-transmission. In the case of the first three, representing spectra of the gas-flame, the electric are, and the sun, nearly all the energy lies above $3^{\mu}$; in that of the gasflame a considerable portion lies below $3^{\mu}$ (and still more in that of the candle-flame, if that were shown, where most of the energy would lie below $3^{\mu}$ or outside the limits of the drawing). The curves then, we repeat, represent equal amounts of energy (which without sensible error we may assume to be all exhibited as heat) and enclose equal areas.

The total area represents in each case the expenditure of a unit of cost in thermal energy, the area between $0^{\mu} \cdot 4$ and $0^{\mu \cdot 7 \text {, }}$ the proportion of this utilized as light; though, as we have just stated, in the case of fig. 4, the representative of the firefly spectrum, only a fraction of this can be shown (owing to the limits of the drawing).

Resuming, then, what we have said, we repeat that nature produces this cheapest light at about one four-hundredth part of the cost of the energy which is expended in the candleflame, and at but an insignificant fraction of the cost of the electric light or the most economic light which has yet been 
Diagram 4.

Four Curves of Equal Areas, showing one unit of heat displayed successively in heat spectrum of Gas, Flectric Arc, Sun and Fire-Fly.

ABScissae. - WAVE Lengths.

Ordinates. - Energy as Heat.

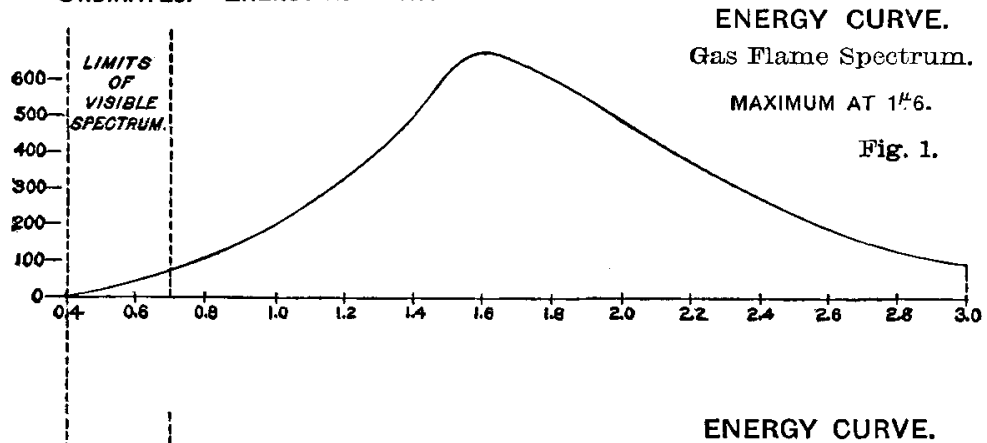

Electric Are Spectrum.
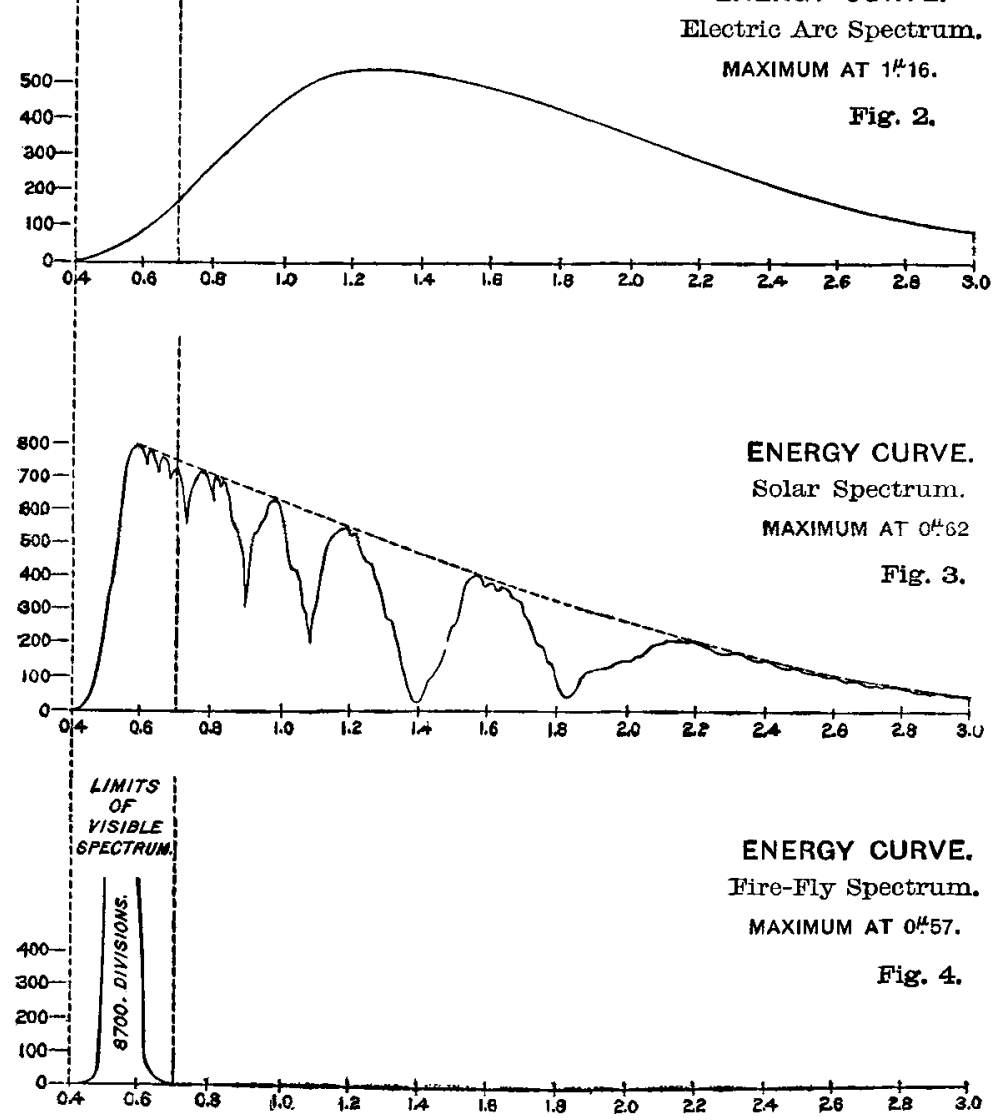
devised; and that, finally, there seems to be no reason why we are forbidden to hope that we may yet discover a method (since such a one certainly exists and is in use on the small scale) of obtaining an enormously greater result than we now do from our present ordinary means for producing light.

APPENDIX.

Determination, in Calories, of the Heat in the Luminous (Abdominal) Radiation of Pyrophorus noctilucus.

The determination is reached by two steps :-(1) The calibration of the galvanometer, so as to give the value of its division in calories; and (2) the inference from the observed deflexion in divisions of the total of calories radiated.

(1) The bolometer, whose face occupied 0.19 square centim. $(a)$, gave a deflexion of 342 divisions $(b)$, at a distance of 25 centim. $(r)$ from a 5 centim. circular aperture filled by a blackened Leslie cube. Seen from the centre of this aperture, the bolometer occupied then $\frac{a}{2 \pi r^{2}}=0.0000484$ of the hemisphere, and would have received this fraction of the total radiation, except that, being placed exactly opposite the radiating surface, more than the mean radiation fell on it in a proportion which calculation shows to be about $\frac{1}{3}$. The fraction of the total radiation which it actually received, then, was $0 \cdot 0000645(c)$.

Accordingly the total radiation would have caused a deflexion $\frac{b}{c}=5,300,000$ divisions.

The surface of the cube was at a temperature of $99^{\circ} \mathrm{C}$., and was limited by the diaphragm to an area of $19 \cdot 6$ square centim. $(d)$. The total radiation from one centimetre, then, would have caused a deflexion of $\frac{b}{c d}=270,400$ div. The temperature of the bolometer, which was that of the apartment, was $20^{\circ} \mathrm{C}$. According to Dulong and Petit's law, the radiation from such a surface at $99^{\circ} \mathrm{C}$. to one at $20^{\circ} \mathrm{C}$. would be 1.11 cal. per minute (e), which does not greatly differ from our own independent determinations; and for 10 sec. $=0.167 \mathrm{~min} .(f)$ (the time of the galvanometer-swing) it equals $0 \cdot 185$ cal. $(e f)$. Hence $\frac{b}{c d e f}=\frac{270400}{0 \cdot 185}=1462000 \mathrm{div}$. is the potentiality of work in 1 calorie, to be expressed in the swing of the galvanometer-needle, and 1 div. $=0 \cdot 000000684$ cal. 
(2) The galvanometer received the fire-fly radiation through a lens which occupied 0.00655 of a hemisphere, and would have transmited this fraction of the total heat except for its position, which caused it to transmit $\frac{1}{3}$ more than the average, which is $0.00873(g)$. The measured radiation from this fractional part gave $0.84 \mathrm{div}$. $(h)$, and $\frac{h}{g}=96.2 \mathrm{div}$. is the deflexion which would be given by the total abdominal emission, or

$$
96.2 \times 0.000000684=0.0000658 \mathrm{cal} .
$$

Since the luminous surface has an area of about $\frac{1}{6}$ square centim., this corresponds to a radiation of 0.00039 per square centim. of radiating surface in the time of the galvanometerneedle's swing, or to $\frac{0 \cdot 0004}{f}=0.0024$ cal. per square centim.
per minute.

(Taking the water-equivalent of the bulb of an ordinary mercurial thermometer 1 centim. in diameter at $0.25 \mathrm{gr}$., we find

$$
\frac{0 \cdot 84 \times \cdot 000000684}{0 \cdot 25}=0^{\circ} \cdot 0000023,
$$

showing that if such a thermometer were placed in the position occupied by the bolometer, its rise during the time of the latter's exposure to the radiation of the insect would be between two and three one-millionths of a Centigrade degree.)

\section{Proceedings of Learned Societies. GEOLOGICAL SOCIETY. \\ [Continued from p. 200.] \\ June 18, 1890.-Dr. A. Geikie, F.R.S., President, in the Chair.}

THE following communications were read:-

1 1. "The Borrowdale Plumbago, its Mode of Occurrence and probable Origin." By J. Postlethwaite, Esq., F.G.S.

After giving details of the mode of occurrence of the plumbago of Borrowdale in veins traversing diabase and diorite, which break through the Volcanic Series of Borrowdale, the author refers to the modes of occurrence of plumbago in other regions, and con trasts these with the surroundings of the Lake-District masses. He points out, that many thousand feet of volcanic rock supervened between the Borrowdale plumbago-bearing rocks and the overlying carbonaceous shales of Silurian age. On the other hand, he finds similarities between the containing rocks in Borrowdale and the diamond- 